\title{
Stimulation of Corticotropin Release by Pentagastrin in Normal Subjects and Patients With Panic Disorder
}

\author{
James L. Abelson, Randolph M. Nesse, and Aaron Vinik*
}

\section{Introduction}

Patients with panic disorder have shown blunted corticotropin (ACTH) responses to corticotropin-releasing hormone (CRH) infusion (RoyByrne et al 1986). The precise mechanism underlying such blunting remains uncertain. Control of the hypotialamic-pituitary-adrenal (HPA) axis involves multiple homonal regulators; but other regulators have received little attention. The availability of other regulators for infusion studies could advance our understanding of HPA axis function and help clarif' the mechanisms underlying the blunted ACTH response to $\mathrm{CRH}$.

Cholecystokinin (CCK) and gastrin are centrally active neurotransmitters (Williams 1982) that appear to co-regulate HPA axis function, most likely through a brain receptor that is responsive to both peptides (Reisine and Jensen 1986; Saito et al 1980). ACTH and/or cortisol release in humans can be stimulated by large CCK-like peptides (Späth-Schwalke et al 1988) and by small gastrinlike fragments (de Montigny 1989; Degli Uberti et al 1983).

Pentagastrin is a synthetic analogue that contains the same carboxy terminus tetrapeptide amide as CCK and gastrin. In one human study

\footnotetext{
From the University of Michigan, Departments of Psychiatry (JLA, RMN) and Endocrinology and Mctabolism (AV). Ann Arbor, MI 48i09-0840.

Address reprint requests to James L. Abelson, M.D., Ph.D., University of Michigan Medical Center, 1500 East Medical Center Drive, Ann Arbor, MI 48109-0840.

Received June 25, 1990; revised November 26, 1990.

*Current address: Director, Diabetes Research Institute, Eastern Virginia Medical School, Norfolk, VA 23510.
}

it has been shown to be an active ACTH secretagogue (Degli Uberti et al 1983), but there are conflicting aninal data (Itoh et al 1979). Its ready availability and proven safety record in human use, along with the evidence that a gastrin/CCK-like peptide may co-regulate HPA activity, make pentagastrin a potentially valuable probe of the human stress-response system. To initiate development of this probe we attempted to confirm that pentagastrin is an ACTH secretagogue in humans and to pilot its use in a clinical population by conducting pentagastrin infusions in ten subjects, five normai controls, and five patients with panic disorder. We report here the ACTH and cortisol responses of these subjects.

\section{Methods}

All subjects gave informed consent, were drugfree for at least 2 weeks prior to study, were medically healthy, and were evaluated using a structured clinical interview. Panic patients met DSM-lil-R criteria for panic disorder but did not meet criteria for current major depression or substance abuse and did not have any history of primary depression or psychosis. Contrel subjects were age and sex matched to the patients and did not meet criteria for any Axis I disorder. Subjects were admitted to a clinical research center the night prior to study. They were awakened at 7:30 AM, and at 8:00 AM an indwelling heparin lock catheter was inserted into an intecubital vein. Three baseline blood samples were drawn, at 8:30, 8:45, and 8:59 
AM. At 9:00 AM pentagastrin (commercially available as Peptavlon, Ayerst Laboratories) was infused into the heparin lock, for $1 \mathrm{~min}$, at a dosage of $0.6 \mu \mathrm{g} / \mathrm{kg}$, in a saline vehicle of less than $1 \mathrm{ml}$. Blood samples were then drawn 1 , $3,5,7,10,15,20,30,45$, and $60 \mathrm{~min}$ after the infusion for ACTH assay and 5, 7, 10, 20, 30,45 , and $60 \mathrm{~min}$ for cortisol assay. ACTH was measured by radioimmunoassay, with a sensitivity of $6 \mathrm{pg} / \mathrm{ml}$ and intraassay and interassay coefficients of variation of less than $10 \%$. Cortisol was measured by high-performance liquid chromatography, with a sensitivity of 0.1 $\mu \mathrm{g} / \mathrm{dl}$ and coefficients of variation of less than 6\%. Anxiety symptoms were monitored repeatedly throughout the procedure, using a modified version of the Acute Panic Inventory (API) (Dillon et al 1987).

\section{Results}

One control subject had a resting norepinephrine level of over $1000 \mathrm{pg} / \mathrm{ml}$ and was dropped from the analyses. This resulted in a sample of nine subjects - a control group of four women (mean age $=28.0 \pm 6.3$ years) and a patient group of four women and one man (mean age $=32.2$ \pm 10.1 years). All five patients with panic disorder had paniclike attacks in response to the pentagastrin iniusion. Only one of the four control subjects had a paniclike attack. These responses have been described elsewhere (Abelson and Nesse 1990).

Analysis of ACTH cata (repeated measures analysis of variance on log-transformed data) revealed a significant hormonal response to the infusion (main effect of time; $F=9.13, p<$ 0.0001 , df $=12,84)$. The ACTH response, shown graphically in Figure 1, began within 3 min of infusion and disappeared within $30 \mathrm{~min}$. It was subsiantial in size, with a mean peak response (postinfusion maximum minus mean baseline) of $79.0 \mathrm{pg} / \mathrm{ml}$. Tukey's test showed significant elevations above baseline levels ( $p$ $<0.05$ ) at $3,5,7$, and $10 \mathrm{~min}$ after infusion (ail subjects combined). Panic patients had elevated mean baseline ACTH levels (patient mean $=74.9 \pm 22.9 \mathrm{pg} / \mathrm{ml}$; control mean $=43.8$

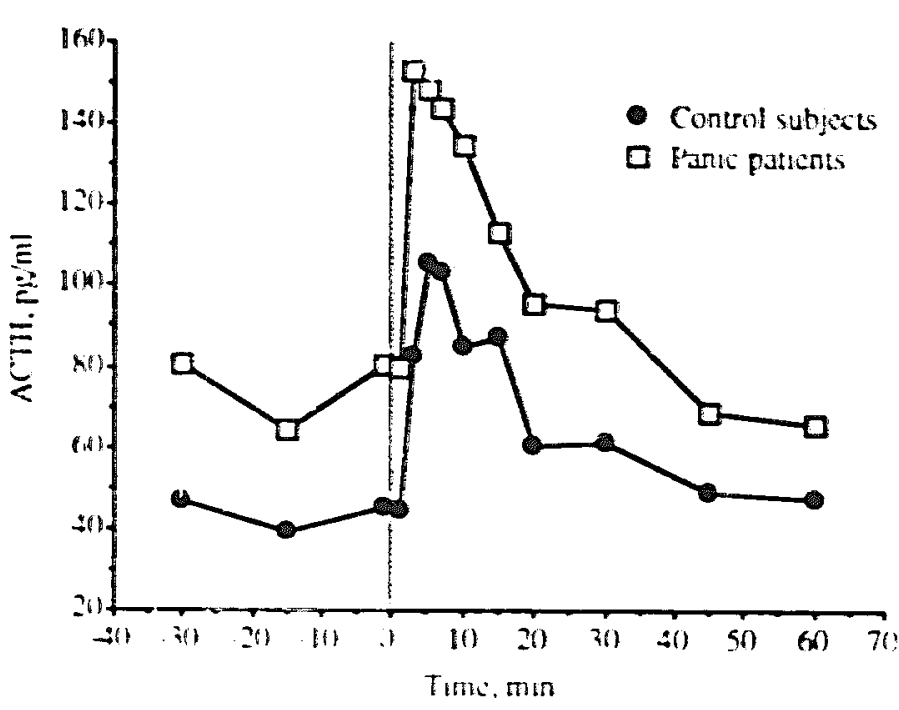

Figure 1. Mean ACTH levels in patients and controls, before and after pentagastrin infusion. Infusion was given at time 0 .

$\pm 15.7 \mathrm{pg} / \mathrm{ml} ; t=2.47, p<0.05, \mathrm{df}=7$ ). The two groups did not differ on any measure of ACTH response to pentagastrin (area under the curve, net response, peak response), but panic patients had higher values on all of these measures. The mean peak response, for example, was $88.6 \mathrm{pg} / \mathrm{ml}$ in patients and $66.9 \mathrm{pg} / \mathrm{ml}$ in controls.

Analysis of cortisol data also revealed a highly significant response to the infusion (main effect of time; $F=13.77, p<0.0001$, df $=9,63$ ). The cortisol response followed the time course expected in response to the ACTH release described above. Tukey's test showed significant elevations above baseline levels $(p<0.05)$ at 10,20 , and $30 \mathrm{~min}$ after the infusion (all subjects combined). Patient and control groups tid not differ in mean baseline cortisol levels (patient mean $=14.6 \pm 4.7 \mu \mathrm{g} / \mathrm{dl}$; control mean $=11.0 \pm 2.5 \mu \mathrm{g} / \mathrm{dl} ; t=1.35, p>0.20, \mathrm{df}$ $=7)$. However, panic patients dio have a significantly greater area under the postinfusion response curve (patient mean $=780 \pm 145$; control mean $=564 \pm 97 ; t=2.53, p<0.05$, $\mathrm{df}=7)$, and the group differences in net response (postinfusion area minus preinfusion area) approached significance (patient mean $=320$ \pm 62 ; control mean $=216 \pm 78 ; t=2.26$, $p<0.06$, df $=7$ ).

The ratio of ACTH to cortisol response (area under postinfusion response curve for $\mathrm{ACTH}$ 
divided by area under the postinfusion response curve for cortisol) was calculated for each subject. The two groups had nearly identical ratios (8.5 \pm 2.5 for panic patients and $8.8 \pm 4.4$ for controls; $t=0.12, p>0.90$, df $=7$ ).

The correlation between mean baseline cortisol and net ACTH response was small and nonsignificant $(r=0.136, p>0.70)$. There was no relationship between net $\mathrm{ACTH}$ response and subjective symptom response to the infusion (calculated by subtracting total symptom severity on the preinfusion API from total peak symptom severity postinfusion; $r=-0.43, p>$ 0.20 ). Peak ACTH response and peak postinfusion symptom levels also showed a nonsignificant, negative correlation $(r=-0.45, p>$ $0.20)$.

\section{Discussion}

The data confirm that pentagastrin produces significant rises in both ACTH and cortisol and demonstrate that this peptide provides an easily used and potent stimulus to the human HPA axis. The mechanism cannot be determined from our data, but the time course of the response and its lack of relationship to basal cortisol levels suggest that it was not mediated by CRH. Anxiety symptoms also do not appear to have mediated the ACTH responses seen. Correlations between symptoms and ACTH responses were insignificant and negative. Those subjects with the most intense paniclike symptoms had the smallest ACTH responses. The three subjects with the largest $A C T H$ responses were the least symptomatic in their groups. Panic attacks themselves do not produce the kind of HPA activation that we saw in response to pentagastrin (Cameron et al 1987; Levin et al 1987; Woods et al 1987). Additional research is necessary to verify our hypothesis that the ACTH response to pentagastrin results from direct pharmacological effect on the pituitary corticotroph cell.

The implications of our patient-control comparisons must be considered tentative until we have enlarged our sample sizes, but the potential utility of this new probe is illustrated by the intriguing possibility that panic patients have
HPA axis responses to pentagastrin that differ from their HPA responses to CRH. Panic patients appear to have normal or increased HPA axis responsivity to pentagastrin (compared with controls they had greater postinfusion cortisol levels, normal ACTH/cortisol ratios, and higher values on all measures of ACTH response), whereas prior reports have demonstrated blunted ACTH responses to $\mathrm{CRH}$ in panic patients (Holsboer et al 1987; Roy-Byme et al 1986). A variety of mechanisms could contribute to differing ACTH responses to two different releasing factors. These include differing sensitivity to glucocorticoid inhibition, specific desensitization of the corticotroph cell to one factor, or differing intracellular mediating mechanisms. It is interesting to note that CRH stimulates ACTH release through an adenylate cyclase-cyclic adenosine monophosphate-dependent process (Axelrod and Reisine 1984); CCK-stimulated release of ACTH does not require cAMP (Reisine and Jensen 1986); and panic patients have reduced platelet adenylate cyclase activity (Charney et al 1989). Before proceeding to mechanistic studies, replication of our pilot findings in larger samples is needed, but subsequent combined use of pentagastrin and $\mathrm{CRH}$ infusion probes may be able to shed light on the mechanisms underlying HPA axis abnormalities in panic.

Our data confirm that pentagastrin stimulates ACTH release in humans and demonstrate the applicability of this neuroendocrine probe to psychiatric research. The data suggest that further study of this probe could provide unique opportunities for more precise elucidation of stress-response system abnormalities in psychiatric disorders.

This research was supported in part by Clinical Research Center grant 5MO1RR00042. The authors wish to thank the CRC nurses for their skilled assistance in data collection.

\section{References}

Abelson JL, Nesse RM (1990): CCK-4 and panic (letter). Arch Gen Psychiatry 47:395.

Axelrod J, Reisine TD (1984): Stress hormones: Their interaction and regulation. Science 224:452-459. 
Cameron OG, Lee MA, Curtis GC, McCann DS (!987): Endocrine and physiological changes during "spontaneous" panic attacks. Psychoneuroendocrinology 12:321-331.

Charney DS, Innis RB, Duman RS, Woods SW, Heninger GR (1989): Platelet alpha-2-receptor binding and adenylate cyclase activity in panic disorder. Psychopharmacology 98:102-107.

de Montigny C (1989): Cholecystokinin tetrapeptide induces panic-like attacks in healthy volunteers. Arch Gen Psychiatry 46:511-517.

Degli Uberti EC, Trasforini G, Margutt: AR, Rotola CA, Pansini R (1983): Effects of pentagastrin on adrenocorticotropin hormone and thyroid-stimulating hormone release in normal subjects. Horm Res 17:74-77.

Dilion Dj, Gorman JM, Liebowitz MR, Fryer AJ, Klein DF (1987): Measurement of lactate-induced panic and anxiety. Psychiatry Res 20:97-105.

Holsboer F, von Bardelben U, Buller R, Heuser I, AS (1987): Stimulation response to corticotropinreleasing hormone $(\mathrm{CRH})$ in patients with depression, alcoholism and panic disorder. Horm Metab Res 16(Suppl):80-88.

Itoh S, Hirota R, Katsuura G, Odaguchi K (1979): Suppressive effect of pentagastrin on piruitary- adrenocortical secretion. Endocrinol Jpr. 26:741744.

Levin AP, Doran AR, Liebowitz MR, et al (1987): Pituitary adrenocortical unresponsiveness in lactate induced panic. Psychiatry Res 21:23-32.

Reisine T, Jensen R (1986): Cholecystokinin-8 stimulates adrenocorticotropin release from anterior pituitary cells. J Pharmacol Exp Ther 236:621626.

Roy-Byme PP, Uhde TW, Post RM, Gallucci W, Chrousos GP, Gold PW (1986): The corticotropinreleasing hormone stimulation test in patients with panic disorder. Am J Psychiatry 143:896-899.

Saito A, Sankaran H, Goldfine ID, Williams JA (1980): Cholecystokinin receptors in brain: Characterization and distribution. Science 208:1155-1156.

Späth-Schwalbe E, Piroth L, Pietrowsky R, Born J, Lorenz Fehm H (1988): Stimulation of the pituitaiy adrenocortical system in man by cerulein, a cholecystokinin-8-like peptide. Clin Physiol Biochem 6:316-320.

Williams JA (1982): Cholecystokinin: A hormone and a neurotransmitter. Biomed Res 3:107-121.

Woods SW, Charney DS, McPherson CA, Gradman AH, Heninger GR (1987): Situational panic attacks: Behavioral, physiologic, and biochemical characterization. Arch Gen Psychiatry 44:365-375. 